\title{
Interatrial Electromechanical Conduction Delay by ECG P-Wave and Echocardiographic Tissue Doppler Imaging for Diabetics Attending Merjan Teaching Hospital, A Comparison Study
}

\author{
Jabbar Sirhan Hassan', Safaa J. Kadhim², Oday J. Al-Salihi ${ }^{3}$ \\ ${ }^{1}$ Dr. Specialist/Babylon Health Director/MOH/Iraq, ${ }^{2}$ Dr. Ass. Prof., Hamuraby College of Medicine, University of \\ Babylon/Iraq, ${ }^{3}$ Dr. Prof., College of Medicine, University of Babylon/Iraq
}

\begin{abstract}
Objectives: The objective was to study the atrial electromechanical P-wave electrocardiography (ECG) gated measurement of conduction times by tissue Doppler echocardiography (TDI) and left atrial mechanical function and volumes, the non-invasive predictors of atrial fibrillation, in diabetics. Methods: The study conducted by analytic case-control study and included 100 adult patients (63 men, 37 women; mean age $50.49 \pm 8.1$ years), diagnosed with diabetes mellitus according to the criteria of the Diabetes Association of America, and 100 adults healthy (50 men; 50 women; average age $49.25 \pm 9.8$ years) as control. Tissue Doppler imaging (TDI) and conventional echocardiography study was done. Assessment of electromechanical delay was done with the onset of the surface ECG P-wave to the systolic a- -wave onset on TDI of the AV valve annulus of the septum, left and right ones. Using the disk method, the left atrial volumes were assessed. The mechanical function and volumes of the left atrium were computed. Results: The E/A and $\mathrm{e}^{-} / \mathrm{a}^{-}$mitral ratio was assessed by the left and septal annuli were the mean difference significantly less in diabetics than in controls $(\mathrm{P}=0.031)$ and $(\mathrm{P}=0.034$ correspondingly. The electromechanical inter-atrial and intra-atrial delay were significantly greater within the diabetics, contrasted to controls $(\mathrm{P}<0.001)$ and $(\mathrm{P}=0.003)$ correspondingly. Volumes of active left atrial emptying (LAAEV) and the ratio of active left atrial ejection (LAAEF) were significantly higher in diabetics in comparison with controls $(\mathrm{P}=0.002)$ and $(\mathrm{P}<0.001)$ correspondingly. Both were significantly correlated to $\mathrm{E} / \mathrm{A}$ and $\mathrm{e}^{-} / \mathrm{a}^{-}$. Conclusions: In diabetics, conduction times of the atrium by TDI and the dispersion of the P-wave by surface ECG were longer. Furthermore, the mechanical functions and volumes of the left atrium were affected by altering diastolic function in diabetics.
\end{abstract}

Keywords: Diastolic function, atrial fibrillation, electromechanical delay, Left atrial mechanical function, diabetic state.

\section{Introduction}

The duration time between atrial mechanical peak contraction and the electrical depolarization of

\section{Corresponding Author:}

Oday J. Al-Salihi

Dr. Prof., College of Medicine, University of Babylon/ Iraq

e-mail: dr.oday78@yahoo.com the atrium is called atrial electromechanical delays (AEMDs). AEMDs prolongation might be considered as a sign to distinguish arrhythmia (PAF) in patients than in control and prediction of PAF occurrence in observational and case-control studies as Badran and his associates found ${ }^{(1)}$. The clinical suggestion supports the opinion that atrial electromechanical conduction delay prolongation suggest left atrial remodeling electricity, that is fundamental for the $\mathrm{AF}$ maintenance ${ }^{(2)}$. It is also an indicator to worse prospects in DM with valvar disease of the heart and $\mathrm{HF}^{(3)}$. Oxidation stress is a principal 
involving feature to endothelial vascular dysfunction in DM. It is ascribed for its multilayered character by lowering available nitric oxide (NO) and provoking pro-inflammatory reactions which aggravate oxidation stress degree. DM upsurges CVD hazard, yet in healthy persons, signifying an important demand to delineate the mechanism ${ }^{(4)}$. Irregularities of atrial transmission were appraised with noninvasive methods by using TDI and ECG in previous studies ${ }^{(5)}$ and also has been determined to be elongated in many diseases that influence the myocardium ${ }^{(6)}$. Although the atrial conduction time indicates the electrical remodeling estimation of atrium, TDI and 2 simple P-wave maximal duration ( $\mathrm{P} \max$ ) and $\mathrm{p} \mathrm{d}$ markers might give information on extending the time of atrial conduction (7). Remodeling of atria, It might be electrical, operational and physical ${ }^{(8)}$. A larger period of pressure (more than five weeks) can lead to damage (fibrosis and apoptosis) irreversibly. The remodeling however, manifests itself in atria as dilation lately.

\section{Methods}

A total of 100 consecutive DM patients were included between the November2019 and May 2020, all participants were conducted by analytic case-control investigation. All sex and gender adult participants who were in sinus rhythm and diabetes mellitus, diagnosed by DM American Association criteria, taking antidiabetic therapy, in addition to adult age matched healthy volunteers, were included in this study. All contributors with a history of CAD, high BP, LVEDD hypertrophy, LVEF under $50 \%$, primary CMP, valvar cardiac disease, arrhythmia, LBBB ECG, abnormal AV conduction, users for drugs that affect conduction system, thyroid dysfunction, electrolyte disturbance, Anemia, CKD, lung disease (COPD, sleep apnea), and inadequate quality of echo study and images of ECG were eliminated from the research. By 4-chamber outlook of heart apex, the pulsated Doppler sample volume was positioned at the LV mitral lateral annulus level, then successively, septal and tricuspid annuli. The period of time since the start on the surface ECG P-wave toward the start of the delayed diastolic $\mathrm{a}^{-}$wave, named PA on TDI, was taken, starting from the lateral mitral annulus (PA lateral), septal mitral annulus (PA septal), the differentiation concerning PA lateral and PA septal (PA lateral- PA septal), was demarcated as intra-left, then septal with tricuspid was demarcated as intra-right atrial, then between mitral and tricuspid as EMD (inter-atrial). All dimensions were documented around a mean of 3 cycles of heart beats (9). Statistics study done by means of SPSS version 23 . Categorical variables were given as percentages and rate of recurrence. Continuous variables were given as (mean $\pm \mathrm{S} \mathrm{D}$ ). T-test of student has been accustomed toward contrasting averages between diabetic group and control. It was used that Chi-square test find the association between categorical variables. Correlation coefficients (r) were accustomed to assess the association between continuous variables. The significance of means was counted by $p$-value at $\leq 0.05^{*}$.

\section{Results}

Basic laboratory and clinical characteristics of 100 diabetics (mean age $50.49 \pm 8.1$ years) likewise 100 normal followers (average age $49.25 \pm 9.8$ years). The following parameters were significant in diabetics in comparison with the control in the following: body mass index $(\boldsymbol{P}=\mathbf{0 . 0 5 *})$ heart rate $(\mathrm{p}=\mathbf{0 . 0 4 9 *})$, lowdensity lipoprotein cholesterol $\left(\mathrm{p}=\mathbf{0 . 0 4 5 ^ { * }}\right)$. White blood cell count $\left(\mathrm{p}=0.022^{*}\right)$ and fasting blood glucose $(\mathrm{p}<\mathbf{0 . 0 0 1 *})$ were considerably increasing in DM using the t-test for continuous variables. In addition, the diameter and volume index of LA were significant in patients with DM $\left(\mathrm{p}=\mathbf{0 . 0 1}\right.$ *) $\left(\mathrm{p}=\mathbf{0 . 0 4 3 ^ { * }}\right)$ respectively. In conventional Doppler echocardiography parameters, there was significantly high means of E/A in control research group $(\mathrm{P}=\mathbf{0 . 0 3 1}$ ), and IVRT were significant $(\mathrm{P}=\mathbf{0 . 0 4 5}$ *) in DM. In tissue Doppler echocardiography for $\mathrm{LV}$ lateral annulus $\overline{\mathrm{e}} / \overline{\mathrm{a}}(\mathrm{P}=\mathbf{0 . 0 3 4}$ *) was significant in control group and $\mathrm{E} / \overline{\mathrm{e}}\left(\mathrm{P}=\mathbf{0 . 0 3 8 ^ { * }}\right)$ was significant in diabetic group. For right ventricle TDI tricuspid annulus, $\overline{\mathrm{e}} / \overline{\mathrm{a}}(\mathrm{P}=\mathbf{0 . 0 3 6}$ *) was significant as shown in table (1).

Table 1: TDI mean variables differences

\begin{tabular}{|l|c|c|c|c|c|c|}
\hline Variable & \multicolumn{2}{|c|}{ Diabetics $(\mathbf{n}=\mathbf{1 0 0})$} & \multicolumn{2}{c|}{ Control (n=100) } & t-test & P-value \\
\hline Age $($ years $)$ & 50.49 & \pm 8.1 & 49.25 & \pm 9.8 & 0.975 & 0.331 \\
\hline BMI $\left(\mathrm{kg} / \mathrm{m}^{2}\right)$ & 31.97 & \pm 2.36 & 30.94 & \pm 2.37 & 3.08 & $0.05^{*}$ \\
\hline BSA $\left(\mathrm{m}^{2}\right)$ & 1.97 & \pm 0.37 & 1.96 & \pm 0.38 & 0.203 & 0.839 \\
\hline SBP $(\mathrm{mmHg})$ & 120.63 & \pm 4.72 & 119.82 & \pm 5.39 & 1.135 & 0.258 \\
\hline
\end{tabular}




\begin{tabular}{|c|c|c|c|c|c|c|}
\hline \multirow{2}{*}{$\begin{array}{l}\text { Variable } \\
\mathrm{DBP}(\mathrm{mmHg})\end{array}$} & \multicolumn{2}{|c|}{ Diabetics $(n=100)$} & \multicolumn{2}{|c|}{ Control $(n=100)$} & \multirow{2}{*}{$\begin{array}{c}\text { t-test } \\
1.574\end{array}$} & \multirow{2}{*}{$\begin{array}{c}\text { P-value } \\
0.117\end{array}$} \\
\hline & 72.13 & \pm 2.97 & 71.41 & \pm 3.47 & & \\
\hline Heart rate $(\mathrm{B} / \mathrm{min})$ & 76.59 & \pm 7.95 & 74.6 & \pm 6.12 & 1.983 & $0.049 *$ \\
\hline $\mathrm{Hb}(\mathrm{g} / \mathrm{d} \mathrm{L})$ & 14.21 & \pm 1.06 & 14 & \pm 0.98 & 1.455 & 0.147 \\
\hline WBC $(103 / \mathrm{mL})$ & 8.43 & \pm 1.40 & 7.97 & \pm 1.36 & 2.306 & $0.022 *$ \\
\hline LDL-C (mg/d L) & 132.48 & \pm 16.02 & 128.25 & \pm 13.48 & 2.02 & $0.045^{*}$ \\
\hline $\mathrm{FBG}(\mathrm{mg} / \mathrm{d} \mathrm{L})$ & 148.6 & $(92-361)$ & 91.67 & $(77-119)$ & 6.385 & $<0.001^{*}$ \\
\hline Creatinine (mg/dl) & 0.8 & \pm 0.101 & 0.775 & \pm 0.1 & 1.759 & 0.08 \\
\hline LVEDD (mm) & 47.59 & \pm 3.18 & 46.82 & \pm 2.4 & 1.933 & 0.055 \\
\hline $\operatorname{LVESD}(\mathrm{mm})$ & 29.37 & \pm 1.96 & 28.87 & \pm 1.84 & 1.86 & 0.064 \\
\hline IVS thickness(mm) & 9.32 & \pm 4.09 & 8.24 & \pm 3.4 & 2.03 & $0.044 *$ \\
\hline PW thickness(mm) & 9.3 & \pm 1.5 & 8.9 & \pm 1.48 & 1.898 & 0.059 \\
\hline LV mass index $(\mathrm{g} / \mathrm{m} 2)$ & 90.26 & \pm 11.81 & 88.94 & \pm 9.18 & 0.882 & 0.377 \\
\hline Aortic diameter (mm) & 28.1 & \pm 1.22 & 27.85 & \pm 1.37 & 1.363 & 0.175 \\
\hline LA-diameter (mm) & 32.8 & \pm 1.98 & 32.2 & \pm 1.21 & 2.586 & $0.01 *$ \\
\hline LA-volume-index (mL/m2) & 31.45 & \pm 2.8 & 30.7 & \pm 2.4 & 2.034 & $0.043^{*}$ \\
\hline LV EF (\%) & 67.2 & \pm 2.8 & 67.37 & \pm 2.1 & -0.486 & 0.63 \\
\hline PAP systolic (mmHg) & 22.16 & \pm 2.19 & 22.07 & \pm 2.05 & 0.29 & 0.765 \\
\hline \multicolumn{7}{|c|}{ 1. Conventional-Doppler Parameters } \\
\hline Mitral E velocity $(\mathrm{cm} / \mathrm{s})$ & 81.79 & \pm 8.30 & 82.43 & \pm 7.6 & -0.569 & 0.57 \\
\hline Mitral A velocity $(\mathrm{cm} / \mathrm{s})$ & 79.2 & \pm 9.32 & 76.85 & \pm 8.25 & 1.888 & 0.06 \\
\hline $\mathrm{E} / \mathrm{A}$ & 1.085 & \pm 0.14 & 1.125 & \pm 0.12 & -2.169 & $0.031 *$ \\
\hline $\mathrm{DT}(\mathrm{m} \mathrm{s})$ & 182.74 & \pm 8.45 & 180.6 & \pm 7.9 & 0.966 & 0.065 \\
\hline IVRT (m s) & 94.27 & \pm 7.90 & 92.64 & \pm 6.2 & 2.021 & $0.045^{*}$ \\
\hline \multicolumn{7}{|c|}{ 2. Tissue Doppler Parameters } \\
\hline \multicolumn{7}{|l|}{ A. LV lateral annulus } \\
\hline $\mathrm{s}^{-}(\mathrm{cm} / \mathrm{s})$ & 10.16 & \pm 1.07 & 10.14 & \pm 1.06 & 0.133 & 0.89 \\
\hline $\mathrm{a}^{-}(\mathrm{cm} / \mathrm{s})$ & 11.56 & \pm 1.35 & 11.2 & \pm 1.3 & 1.921 & 0.06 \\
\hline $\mathrm{e}^{-}(\mathrm{cm} / \mathrm{s})$ & 11.02 & \pm 1.21 & 11.32 & \pm 1.09 & -1.842 & 0.067 \\
\hline $\mathrm{e}^{-} / \mathrm{a}^{-}$ & 0.98 & \pm 0.158 & 1.025 & \pm 0.140 & -2.132 & $0.034 *$ \\
\hline $\mathrm{E} / \mathrm{e}^{-}$ & 7.35 & \pm 2.4 & 6.7 & \pm 1.96 & 2.098 & $0.038^{*}$ \\
\hline MPI & 0.61 & \pm 0.08 & 0.592 & \pm 0.07 & 1.693 & 0.092 \\
\hline \multicolumn{7}{|l|}{ B. RV lateral annulus } \\
\hline $\mathrm{s}^{-}(\mathrm{cm} / \mathrm{s})$ & 16.7 & \pm 2.45 & 16.57 & \pm 2.92 & 0.341 & 0.73 \\
\hline $\mathrm{a}^{-}(\mathrm{cm} / \mathrm{s})$ & 18 & \pm 3.4 & 17.6 & \pm 3.2 & 0.857 & 0.393 \\
\hline $\mathrm{e}^{-}(\mathrm{cm} / \mathrm{s})$ & 12.96 & \pm 2.87 & 13.48 & \pm 3.2 & -1.21 & 0.23 \\
\hline $\mathrm{e}^{-} / \mathrm{a}^{-}$ & 0.72 & \pm 0.29 & 0.81 & \pm 0.31 & -2.12 & $0.036^{*}$ \\
\hline
\end{tabular}

P-wave indicators and parameters of TDI have been taken in table 3. $\mathrm{P}$ max duration $(\mathrm{p}=\mathbf{0 . 0 1 9 *})$ and $\mathrm{Pd}(\mathrm{p}<$ $\left.\mathbf{0 . 0 0 1}^{*}\right)$ were considerably larger in DM respectively. The duration of $\mathrm{P}$ min was shorter in patients with $\mathrm{DM}(\mathrm{p}$
$=0.031 *)$. The duration of conduction delay in tricuspid lateral PA $(\mathrm{p}<\mathbf{0 . 0 0 1}$ *), septum PA $(\mathrm{p}<\mathbf{0 . 0 0 1} *)$ and MV PA $(p<0.001 *)$ have been significantly elongated in patients with DM in comparison to control respectively. 
In addition, the ratio of conduction delay duration for each annulus to LA diameter were significantly more in $\mathrm{DM}$ in comparison with controls. In addition, the inter atrial $(\mathrm{p}<0.001 *)$, right intra-atrial $(\mathrm{p}=\mathbf{0 . 0 0 3} *)$ and left intra-atrial $(\mathrm{p}=\mathbf{0 . 0 0 4} *)$ EMD were significantly higher in patients with DM than in controls correspondingly. the volume of the active emptying of the left atrium (LAAEV) and the fraction (LAAEF) were significantly greater in diabetics than in controls $(\mathrm{p}=\mathbf{0 . 0 0 4} *)$. LAAEF and LAAEV were significantly correlated with septal and lateral, E/A, $\mathrm{e}^{-} / \mathrm{a}^{-}$. Maximum left atrial volume (V $\max )$ mean difference $(\mathrm{P}=\mathbf{0 . 0 1 9 *})$ was significantly more in diabetics. Presystolic atrial volume $(\mathrm{V} p)(\mathrm{p}$ $\left.=0.036^{*}\right)$ were highly significant in diabetics. The minimum volume ( $\mathrm{V} \mathrm{min}$ ), the volume of passive left atrial emptying (LAPEV) means were lower in diabetic than control means. We found that conduit left atrium volume $(\mathrm{CV})$ and left atrial total emptying volume (LATEV) were statistically significant in diabetics than control.

Table 3: Mean difference variables in cardiac atrium

\begin{tabular}{|c|c|c|c|c|c|c|}
\hline \multirow{2}{*}{$\frac{\text { Variable }}{P \max (\mathrm{m} \mathrm{s})}$} & \multicolumn{2}{|c|}{ Diabetics $(n=100)$} & \multicolumn{2}{|c|}{ Control $(n=100)$} & \multirow{2}{*}{$\begin{array}{r}\text { t-test } \\
2.365\end{array}$} & \multirow{2}{*}{$\frac{\text { P-value }}{0.019 *}$} \\
\hline & 104.7 & \pm 9.5 & 101.8 & \pm 7.75 & & \\
\hline $\mathrm{P} \min (\mathrm{m} \mathrm{s})$ & 65.95 & \pm 4.54 & 67.1 & \pm 4.41 & -1.817 & $0.031 *$ \\
\hline $\mathrm{Pd}(\mathrm{m} \mathrm{s})$ & 39 & \pm 5.20 & 34.05 & \pm 3.11 & 8.252 & $<0.001 *$ \\
\hline PA- lateral (m s) & 63.69 & \pm 4.59 & 52.87 & \pm 3.33 & 19.08 & $<0.001^{*}$ \\
\hline PA -septum (m s) & 55.22 & \pm 4.59 & 46.66 & \pm 3.84 & 14.304 & $<0.001^{*}$ \\
\hline $\mathrm{PA}$-tricusp. $(\mathrm{m} \mathrm{s})$ & 46.2 & \pm 4.52 & 40.51 & \pm 2.97 & 10.521 & $<0.001 *$ \\
\hline PA-lat/LA-diam (ms/mm) & 1.877 & \pm 0.15 & 1.68 & \pm 0.09 & 11.262 & $<0.001^{*}$ \\
\hline PA-sept/LA-diam (mS/mm) & 1.62 & \pm 0.14 & 1.48 & \pm 0.09 & 8.412 & $<0.001 *$ \\
\hline PA-tricus/LA-diam(mS/mm) & 1.35 & \pm 0.13 & 1.3 & \pm 0.10 & 3.049 & 0.003 \\
\hline PA-lat-PA-tricus(m s) & 17.48 & \pm 3.90 & 12.21 & \pm 2.12 & 11.872 & $<0.001 *$ \\
\hline PA-sep-PA tricus.(m s) & 9.07 & \pm 6.3 & 6.9 & \pm 3.4 & 3.031 & $0.003 *$ \\
\hline PA-lat-PA sep (m s) & 7.2 & \pm 5.6 & 5.3 & \pm 3.4 & 2.9 & $0.004 *$ \\
\hline $\mathrm{V} \max , \mathrm{mL} / \mathrm{m}^{2}$ & 30.6 & \pm 7.76 & 28.58 & \pm 6.98 & 1.935 & 0.054 \\
\hline $\mathrm{V} \mathrm{p}, \mathrm{mL} / \mathrm{m}^{2}$ & 21 & \pm 7.3 & 19.1 & \pm 5.2 & 2.12 & $0.036^{*}$ \\
\hline $\mathrm{V} \min , \mathrm{mL} / \mathrm{m}^{2}$ & 10.69 & \pm 1.71 & 12.9 & \pm 6.2 & -2.841 & $0.005^{*}$ \\
\hline $\mathrm{LAPEV}, \mathrm{mL} / \mathrm{m}^{2}$ & 9.31 & \pm 5.3 & 10.39 & \pm 4.1 & -1.836 & 0.068 \\
\hline LAPEF, \% & 0.31 & \pm 0.12 & 0.35 & \pm 0.17 & -1.922 & 0.056 \\
\hline $\mathrm{CV}, \mathrm{mL} / \mathrm{m}^{2}$ & 16.3 & \pm 4.83 & 15 & \pm 3.76 & 2.124 & $0.03 *$ \\
\hline $\mathrm{LAAEV}, \mathrm{mL} / \mathrm{m}^{2}$ & 10.97 & \pm 4.75 & 9.17 & \pm 2.89 & 3.237 & 0.002 \\
\hline LAAEF, $\%$ & 0.508 & \pm 0.153 & 0.432 & \pm 0.17 & 3.323 & $<0.001 *$ \\
\hline $\mathrm{LATEV}, \mathrm{mL} / \mathrm{m}^{2}$ & 20.84 & \pm 7.3 & 18.2 & \pm 5.4 & 2.907 & $0.004 *$ \\
\hline
\end{tabular}

study of the association amongst diastolic function and the considerations representing the mechanical left atrial function and volumes revealed that there had been a significantly negative correlation among LAAEF, LAAEV with mitral $\mathrm{E} / \mathrm{A}$ fraction $(\mathrm{r}=-0.295, \mathrm{p}<0.007$; $\mathrm{r}=-0.450, \mathrm{p}=\mathbf{0 . 0 0 0}$, correspondingly), lateral mitral $\mathrm{e}^{-} / \mathrm{a}^{-}(\mathrm{r}=-0.280, \mathrm{p}=\mathbf{0 . 0 2 0} ; \mathrm{r}=-0.263, \mathrm{p}=\mathbf{0 . 0 1 8}$, correspondingly), then tricuspid $\mathrm{e}^{-} / \mathrm{a}^{-}(\mathrm{r}=-0.342, \mathrm{p}=$ 0.003; $\mathrm{r}=-0.416, \mathrm{p}=\mathbf{0 . 0 0 6}$, correspondingly). In the same way, there has been a significant though fragile negative correlation between $\mathrm{E} / \mathrm{A}$ ratio and interatrial EMCD, LAEMCD $(\mathrm{r}=-0.295, \mathrm{p}=\mathbf{0 . 0 0 4} ; \mathrm{r}=$ $-0.382, \mathrm{p}=\mathbf{0 . 0 0 0}$, correspondingly). We presented the investigation of multivariate regression upon intra-atrial EMCD, interatrial EMCD in addition to LAEMCD in isolation. Analysis of Regression showed the chief factors associated with LAEMCD which were mitral E/A fraction, tricuspid $\mathrm{e}^{-} / \mathrm{a}^{-}$, and $\mathrm{FBG}(\beta=-0.34, \mathrm{p}=\mathbf{0 . 0 6} ; \beta$ 
$=0.31, p=0.043 ; \beta=0.36, p=0.002$, correspondingly). Alternatively, the principal factors correlated to interatrial EMCD have been BMI, FBG, then tricuspid $\mathrm{e}^{-} /$ $\mathrm{a}^{-}(\beta=0.30, p=0.006 ; \beta=0.39, p=0.001 ; \beta=0.37$, $\mathrm{p}=\mathbf{0 . 0 0 9}$, correspondingly). No connection has been presented among age, sex and atrial EMCD. Correlation relationship analysis displayed a positive relation between inter-atrial EMD and $\mathrm{Pd}(\mathrm{r}=0.432, \mathrm{p}=\mathbf{0 . 0 0 1})$ and positive correlation between LA-size $(\mathrm{r}=0.430, \mathrm{p}=$ 0.001 ) figure (3).

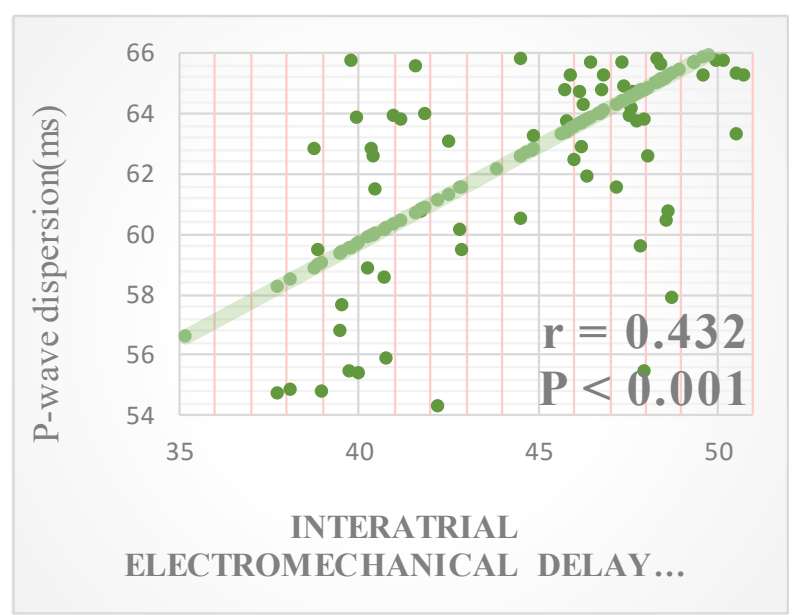

Figure 3: Correlation between $P$ d and AEMCD and Correlation between LA-volume index and IAEMCD

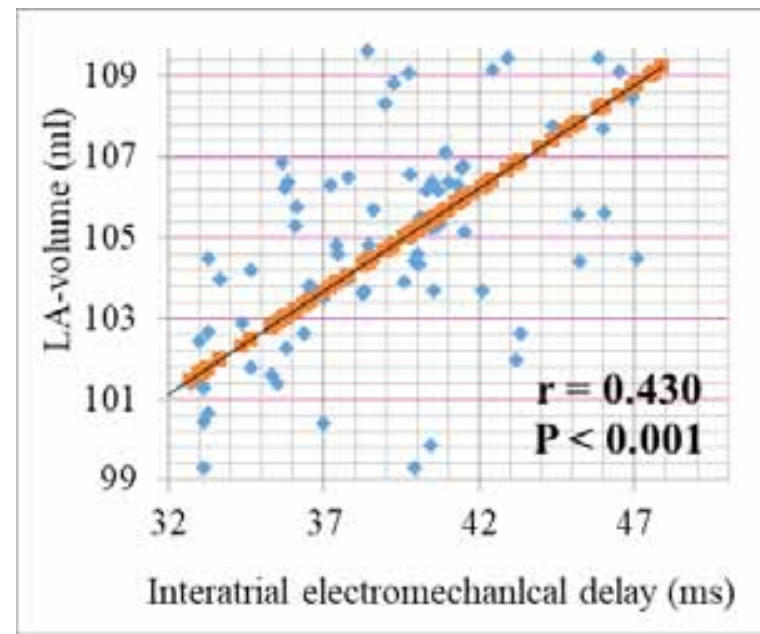

Interatrial electromechanlcal delay (ms)

\section{Discussion}

In this research, the $\mathrm{P}$-wave maximum and $\mathrm{P}$-wave dispersion found to be increased significantly in DM contrasted to control. P-wave minimum was significant in control. The time of EMCD in mitral, septal and tricuspid annuli relative to LA diameter were highly significant in DM. Also, we were very importantly found that the inter-atrial, left intra-atrial and right intra-atrial electro-mechanical conduction delay were significantly prolonged in DM contrasted with control. These our findings were stated by many studies said that the change relating the minimal and maximal Pwave time on surface ECG, is an ECG sign that has been linked with intermittent conduction and tissue inhomogeneity of sinus stimulus reproduction ${ }^{(10)}$. The association between the increment of inter-atrial and intra-atrial delay conduction had a prognostic effect by producing arrhythmia as paroxysmal atrial fibrillation (PAF) has been thoroughly acknowledged ${ }^{(11)}$. Though atrial conduction phase is intensely suggestive of atrial electrical remodeling, TDI and 2 easy ECG markers for P-max. and $\mathrm{P}$-wave dispersion $(\mathrm{P} \mathrm{d}$ ) may give statistics going on for elongation of the atrial conduction interval $^{(12)}$. 
results in harmony with Mahfouz who concluded that there is an important correlation between $\mathrm{AF}$ and diastolic dysfunction, caused by boosted filling pressure and LA stretching in the nonexistence of structural cardiac disorder. According to Mahfouz ${ }^{(14)}$, we located a bigger LA diameter for the DM than in the control group. The mechanical function of LA is a significant component of LV filling. LA displays as storage during systole, as a passage at the initiation of diastole and as a vigorous contractile chamber at the diastole ending (15). The LA function automatically enables the transition between the flow in the pulmonary circulation and the paroxysmal filling of the LV ${ }^{(15)}$. Through diastole, LA is directly exposed to the LV pressure, that increases when the diastolic function of the $\mathrm{LV}$ is compromised ${ }^{(16)}$. LAAEV and LAAEF were also considerably advanced in DM matched to the control for our research. Diastolic function calculated in TDI and conventional echocardiography that have been considerably further compromised in DM than in the control. The significant rise in LAAEV and LAAEF in this study suggests that compensatory LA contraction is important in the diastolic part. The significant relation between LAAEV and LAAEF and the factors that signify diastolic disorders support our suggestion. LAPEV significant mean difference was lower in diabetics in this study. In agreement with the former analyses, Gallen realized that with DM, the LA transmission turn into slow and the LA compliance decreases, signifying the manifestation of DM associated LA wall remodeling ${ }^{(17)}$, also Thomas and associates displayed that DM is a notorious reason of atrial-ventricular conduction delay along with the augmented incidence of $\mathrm{AF}^{(18)}$, so this study was showed direct association between atrial EMD and DM.

\section{Conclusions}

In diabetics, conduction times of the atrium by TDI and the dispersion of the P-wave by surface ECG were longer. Furthermore, the mechanical functions and volumes of the left atrium were affected by altering diastolic function in diabetics.

Ethical Clearance: The Research Ethical Committee at scientific research by ethical approval of both MOH and MOHSER in Iraq.

\section{Conflict of Interest: None}

Funding: Self-funding

\section{References}

1. Badran HM, Faheem N, Wassely KW, Yacoub M. Relationship of left atrial mechanics to electrical activity on surface electrocardiography in idiopathic dilated cardiomyopathy. Glob Cardiol Sci Pract. 2019;2019(1).

2. Jaime SJ. Effects of Twelve Weeks of Whole-Body Vibration Training and Low-Intensity Resistance Exercise Training on Arterial Function, Muscle Strength, and Physical Performance in Dynapenic Postmenopausal Women. 2017;

3. Sargento L, Vicente Sim $\sim\{0\}$ es A, Longo S, Lousada N, Palma dos Reis R. Left atrial function index predicts long-term survival in stable outpatients with systolic heart failure. Eur Hear Journal-Cardiovascular Imaging. 2017;18(2):11927.

4. Smeets ETHC, Mensink RP, Joris PJ. Dietary macronutrients do not differently affect postprandial vascular endothelial function in apparently healthy overweight and slightly obese men. Eur J Nutr. 2020;1-9.

5. Mascolo A, Urbanek K, De Angelis A, Sessa M, Scavone C, Berrino L, et al. Angiotensin II and angiotensin 1-7: which is their role in atrial fibrillation? Heart Fail Rev. 2020;25(2):367-80.

6. Zhao J, Zhou D, Chen M, Zhuo C, Lin Z, Zheng L, et al. CHA2DS2-VASc and SAMe-TT2R2 scores as predictors of recurrence for nonvalvular atrial fibrillation patients on vitamin $\mathrm{K}$ antagonists after radiofrequency catheter ablation. J Cardiovasc Med. 2020;21(3):200-8.

7. Ocal AG, Ocal L, Kup A, Eren H, Tezcan ME. Colchicine's Effects on Electrocardiographic Parameters in Newly Diagnosed Familial Mediterranean Fever Patients. Z Rheumatol. 2020;79(2):210-5.

8. Malagoli A, Rossi L, Bursi F, Zanni A, Sticozzi C, Piepoli MF, et al. Left atrial function predicts cardiovascular events in patients with chronic heart failure with reduced ejection fraction. J Am Soc Echocardiogr. 2019;32(2):248-56.

9. Lazzerini PE, Laghi-Pasini F, Acampa M, Srivastava U, Bertolozzi I, Giabbani B, et al. Systemic Inflammation Rapidly Induces Reversible Atrial Electrical Remodeling: The Role of Interleukin-6Mediated Changes in Connexin Expression. J Am Heart Assoc. 2019;8(16):e011006. 
10. Dincgez Cakmak B, Dundar B, Ketenci Gencer F, Turker U, Kanat S. P-wave and QT dispersion in hypertensive disorders of pregnancy. J Matern Neonatal Med. 2019;32(24):4051-9.

11. Aksu U. The relationship between $P$ wave dispersion and left atrial volume index in patients with metabolic syndrome. Ann Med Res. 2019;26(6):1090-3.

12. Tanaka S, Noda T, Kawasaki M, Segawa T, Tsugita $\mathrm{N}$, Fuseya T, et al. Relationship between electrical conduction and phasic left atrial function: P-wave signal-averaged electrocardiography and timeleft atrial volume curve assessments using twodimensional speckle-tracking echocardiography. Heart Vessels. 2019;34(7):1212-20.

13. Saqar AA. Left Ventricular Diastolic Dysfunction In Normotensive Type II Diabetic Patients In ThiQar At 2019. Ministry of Higher Education; 2019.

14. Mahfouz RA, Gouda M, Galal I, Ghareb MS. Interatrial septal fat thickness and left atrial stiffness are mechanistic links between nonalcoholic fatty liver disease and incident atrial fibrillation. Echocardiography. 2019;36(2):249-56.

15. Athayde GRS, Nascimento BR, Elmariah S, LodiJunqueira L, Soares JR, Saad GP, et al. Impact of left atrial compliance improvement on functional status after percutaneous mitral valvuloplasty. Catheter Cardiovasc Interv. 2019;93(1):156-63.

16. Chirinos JA, Sardana M, Satija V, Gillebert TC, De Buyzere ML, Chahwala J, et al. Effect of obesity on left atrial strain in persons aged 35-55 years (The Asklepios Study). Am J Cardiol. 2019;123(5):85461.

17. Gallen R, Herczeg S, Mcgorrian C, Carron J, Walsh K, Keelan T, et al. P333 Left atrial function by echocardiography is independent of degree of left atrial electrical scar. EP Eur. 2020;22 (Supplement_1):euaa162-153.

18. Thomas L, Marwick TH, Popescu BA, Donal E, Badano LP. Left atrial structure and function, and left ventricular diastolic dysfunction: JACC state-of-the-art review. J Am Coll Cardiol. 2019;73(15):1961-77. 